\title{
HANGING VESICAL CALCULUS: A RARE CASE REPORT
}

\author{
Aysha Shaheen ${ }^{1}$, Vetrichandar $S^{2}$
}

${ }^{1}$ Consultant Urogynaecologist, Department of Urology, Aysha Urology and Gynaec Clinic, Dr. MGR Medical University, Chennai. ${ }^{2}$ Consultant Urologist, Department of Urology, Aysha Urology and Gynaec Clinic, Dr. MGR Medical University, Chennai.

\section{ABSTRACT}

A hanging intravesical calculus on the dome of the urinary bladder is rare. It usually hints that the bladder stone encrusts sutures or devices. Here we present a rare case of hanging vesical calculus formed on a prolene material, which was used for closure of an emergency midline laparotomy. The complication can be prevented by the routine use of absorbable material in sutures outside the urinary bladder. No use of any suture through the urinary bladder and cystoscopic double-checking.

\section{KEYWORDS}

Hanging Vesical Calculus, Foreign body Calculus, Cystolitholapaxy, Cystolithotomy.

HOW TO CITE THIS ARTICLE: Shaheen A, Vetrichandar S. Hanging vesical calculus: a rare case report. J. Evolution Med. Dent. Sci. 2016;5(59):4142-4144, DOI: 10.14260/jemds/2016/946

\section{INTRODUCTION}

Vesical calculus occurs most commonly as a result of either migration from the kidney or prolonged urinary stasis in the bladder. Any prior pelvic, inguinal or rarely abdominal surgery in the proximity of the bladder, in which non-absorbable suture materials may complicate the calculus process and cause recurrent UTI.

\section{CASE PRESENTATION}

Here we report a case of 40 years male, a daily wage worker admitted with h/o urgency, frequency and dysuria for 6 years with no h/o haematuria, calculuria or any obstructive LUTS.

He was having recurrent UTI which was treated medically with antibiotics. He had undergone emergency laparotomy 15 years ago for? Intestinal obstruction and open cholecystectomy one year ago. Physical examination was unremarkable. Ultrasonography (USG) showed an echogenic, fixed intraluminal lesion in the bladder (Fig. 1). X-ray showed a well-circumscribed radio-opaque shadow in the bladder region (Fig. 2). CT KUB showed an intravesical $2 * 1.5 \mathrm{~cm}$ hyperdense lesion, adherent to the anterior bladder wall (Fig. 3). Upper tract was normal. Cystoscopic evaluation was performed under anaesthesia and confirmed presence of $2 \mathrm{~cm}$ calculus formed around prolene knot fixed to the bladder wall (Fig. 4).

These sutures had been strangely included in the bladder wall during midline laparotomy closure. Since the prolene knot was attached firmly with the rectus sheath, we decided to open and cystolithotomy was done (Fig. 5). Prolene suture was detached from bladder. The bladder calculus was removed and analysis revealed calcium oxalate as composition. The suprapubic catheter and urethral Foley were removed at first week and second week respectively. The patient discharged from hospital with good condition and negative urine culture.

Financial or Other, Competing Interest: None.

Submission 15-06-2016, Peer Review 29-06-2016,

Acceptance 15-07-2016, Published 25-07-2016.

Corresponding Author:

Dr. Aysha Shaheen,

No. 83,

Thirumangalam Road,

Villiwalkam,

Chennai-49.

E-mail: ayshaurogynec@gmail.com

DOI: $10.14260 /$ jemds $/ 2016 / 946$

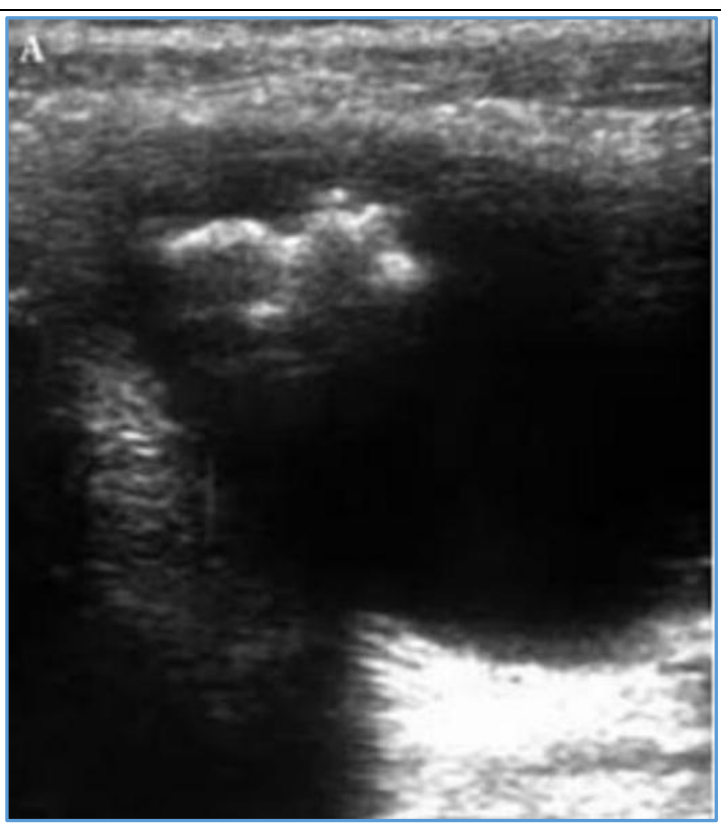

Fig. 1: USG Bladder-Echogenic Lesion in the Dome

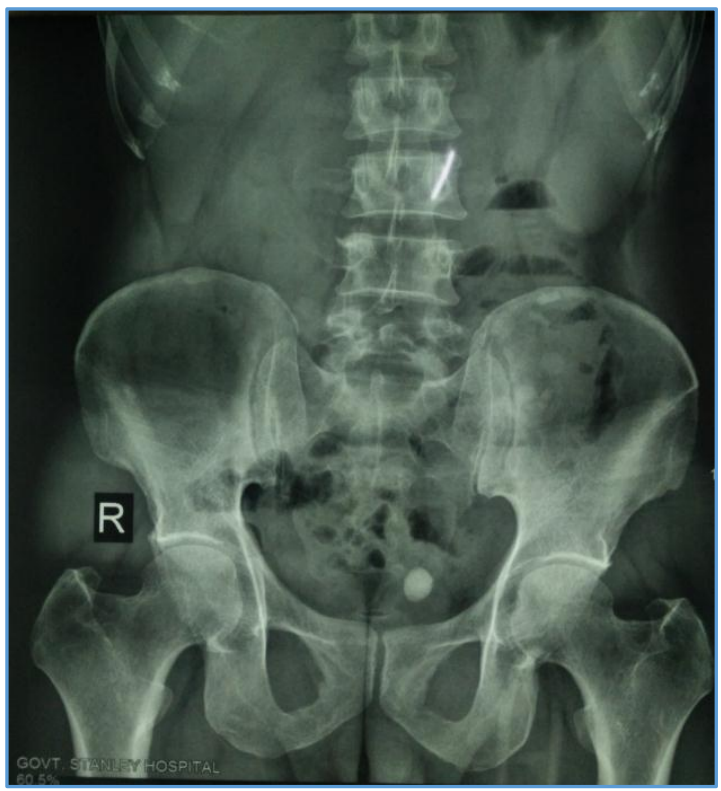

Fig. 2: X-Ray - Radio-opaque Calculus in Bladder 


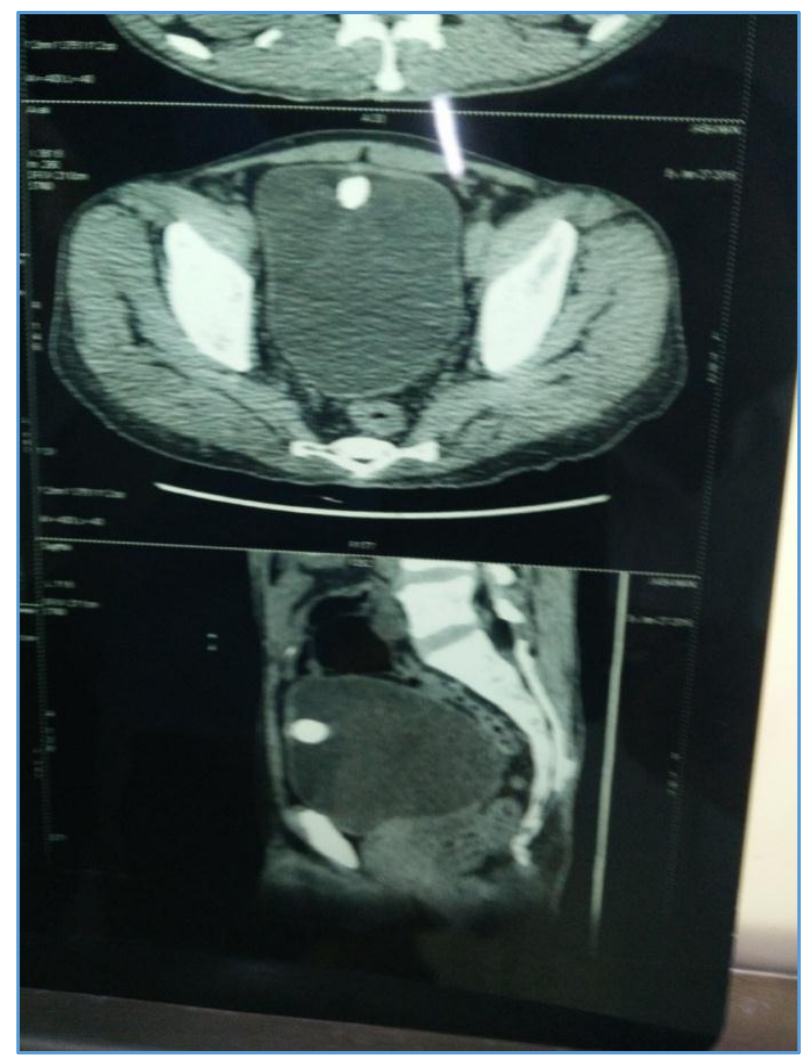

Fig. 3: CT-Hyperdense Hanging Calculus

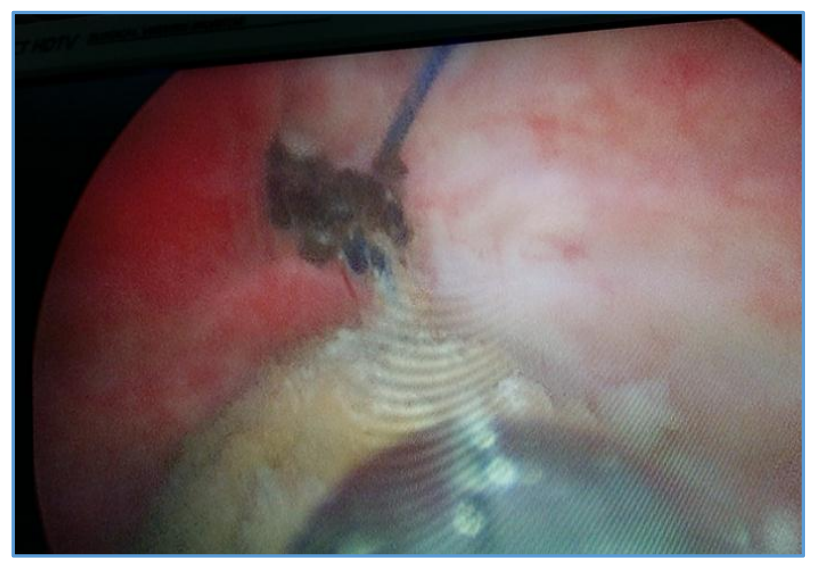

Fig. 4: Stone Formed on Prolene Suture

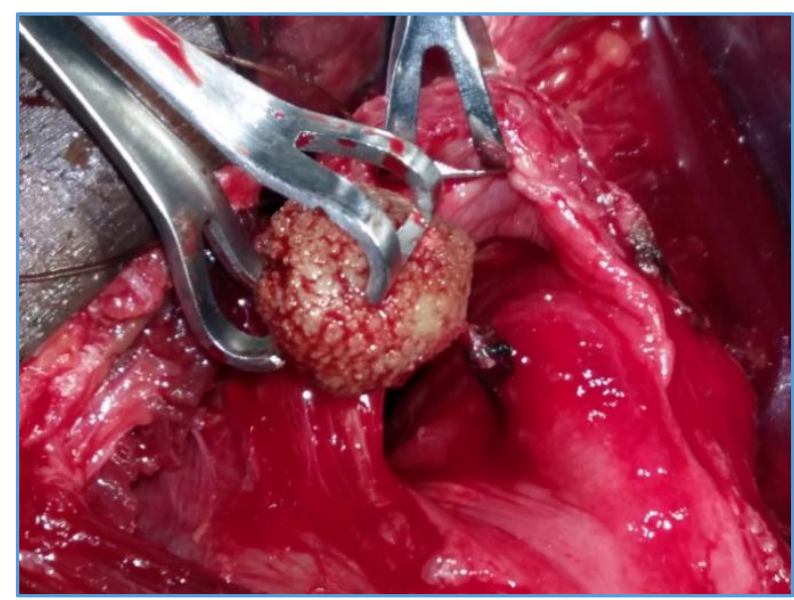

Fig. 5: Stone Retrieval by Open Cystolithotomy

\section{DISCUSSION}

A renal calculus may migrate to the bladder or it may form in the bladder itself due to urinary stasis. Bladder outlet obstruction may be due to cystocele, neurogenic bladder or a foreign body in the bladder.(1) Urinary tract infection is implicated as the cause of stones in about $15 \%$ of stone formers and it will complicate the management of pre-existent calculi. If not treated it may cause renal damage or may lead on to life-threatening conditions.(2) Bladder stones can adhere to the bladder wall because of local inflammation and these are known as "hanging" bladder stones.(1) Any foreign body may act as a leading point for developing bladder calculi. These stones appear as a fixed echogenicities on USG. Intraluminal portion of deep sutures can act as a nidus for stone formation. $(3,4)$ Other surgical operations such as exstrophy repair.(5) stress urinary incontinence surgery.(6) prostatectomy.(7) caesarean section.(8) etc., may also cause bladder stone formation due to usage of non-absorbable sutures. Our case is probably first of its kind in which bladder calculus was formed after emergency laparotomy. While closing the rectus sheath in the lower end they have included the bladder wall and prolene knot acted as a nidus. Many animal studies have shown the importance of suture materials in recurrent cystolithiasis. ${ }^{(9)}$

\section{CONCLUSION}

A hanging intravesical calculus on the dome of the urinary bladder is rare. It usually hints that the bladder stone encrusts sutures or devices. The non-absorbable suture material is the most common cause for hanging vesical calculus. The complication can be prevented by the routine use of absorbable material in sutures outside the urinary bladder; no use of any suture through the urinary bladder and layer by layer closure of laparotomy wounds under direct vision. Cystoscopic double-checking may be done in doubtful cases.

\section{REFERENCES}

1. Thurston W, Wilson SR. Diagnostic ultrasound. In: Rumack CM, Wilson SR, Charboneau JW, eds. $3^{\text {rd }}$ ed. St. Louis: Mosby 2005:321-94.

2. Thomas B, Tolley D. Concurrent urinary tract infection and stone disease: pathogenesis, diagnosis and management. Nat Clin Pract Urol 2008;5(12):668-75.

3. Colegate-Stone TJ, Raymond T, Khot U, et al. Laparoscopic management of iatrogenic bladder injury and bladder stone formation following laparoscopic inguinal herniorrhaphy. Hernia 2008;12(4):429-30.

4. Ngo T. Surgical mesh used for an inguinal herniorrhaphy acting as a nidus for a bladder calculus. Int J Urol 2006;13(9):1249-50.

5. Rub R, Madeb R, Morgenstern S, et al. Development of a large bladder calculus on sutures used for pubic bone closure following exstrophy repair. World J Urol 2001;19(4):261-2.

6. Huang WC, Yang JM. USG appearance of a bladder calculus secondary to a suture from a bladder neck suspension. J Ultrasound Med 2002;21(11):1303-5.

7. Cursio $\mathrm{R}$, Choquenet $\mathrm{C}$. Iatrogenic bladder stone formation on absorbable suture 3-years after radical prostatectomy. Minerva Urol Nefrol 2002;54(2):127-8. 
8. Su CM, Lin HY, Li CC, et al. Bladder stone in a woman after caesarean section: a case report. Kaohsiung J Med Sci 2003;19(1):42-4.
9. Kosan M, Gonulalan U, Ozturk B, et al. Tissue reactions of suture materials (polyglactine 910, chromed catgut and polydioxanone) on rat bladder wall and their role in bladder stone formation. Urol Res 2008;36(1):43-9. 